\title{
LARGE-AREA VIRTUAL FORESTS FROM TERRESTRIAL LASER SCANNING DATA
}

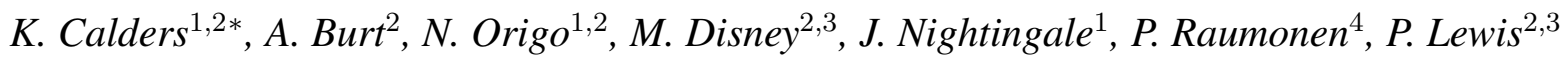 \\ ${ }^{1}$ National Physical Laboratory, UK \\ ${ }^{2}$ University College London, UK \\ ${ }^{3}$ NERC National Centre for Earth Observation, UK \\ ${ }^{4}$ Tampere University of Technology, Finland
}

\begin{abstract}
Combining virtual forests with radiative transfer is a powerful tool to calibrate and validate ground-based, airborne and spaceborne sensors. In this set-up, we can control and calculate all aspects of the forest structure and the simulated signal, which would not be possible using measured data only. Terrestrial laser scanning (TLS) enables us to measure forest structure directly with high detail. We present a processing chain that uses TLS data as input data to assess the end-to-end traceability of various in situ LAI and fAPAR products via radiative transfer modelling. Tree reconstruction from TLS data is used to represent the explicit 3D forest structure in radiative transfer models.
\end{abstract}

Index Terms - Terrestrial LiDAR, Forestry, 3D modelling, Calibration and Validation, radiative transfer

\section{INTRODUCTION}

The date of leaf emergence in spring is a UK climate indicator and has occurred progressively earlier since the 1960s [1]. Forest ecosystems cover approximately 4 billion hectares or about $31 \%$ of the land surface on the Earth and spaceborne remote sensing is critical to collect global data that underpins climate change research efficiently. These remote sensing observations are used to derive biophysical essential climate variables (ECVs) that enable large-scale evaluation of the response of vegetation to climate change. ECVs such as plant/leaf area index (PAI/LAI) and fraction of absorbed photosynthetically active radiation (fAPAR) are good indicators of small changes in terrestrial vegetation over time. In situ estimates or reference products from other earth observation missions are generally used to validate spaceborne ECV products. However, true validation (i.e. direct comparison) and end-to-end traceability of in situ observations and satellitederived ECV products are difficult since most of these methods estimate biophysical properties indirectly using a range of hypotheses and assumptions.

Terrestrial laser scanning (TLS), also referred to as terrestrial LiDAR (light detection and ranging), provides highly

\footnotetext{
*kim.calders@npl.co.uk
}

detailed, objective and robust 3D data of the forest structure. The development of terrestrial laser scanners has lagged behind the development of airborne LiDAR systems, which were used for forest measurement from the mid-1980s. Recent years showed substantial progress in the development and validation of terrestrial laser scanning methods to support forest inventory [2].

Different methods and algorithms have demonstrated the reconstruction of tree models from terrestrial laser scanning data $[3,4,5,6,7]$. Most of these methods work well for modelling the branching architecture, but do not take into account leaf modelling or are computationally expensive, which limits upscaling to large area modelling.

In this paper we describe a processing chain that uses terrestrial laser scanning data as input data to quantify the endto-end traceability of various in situ LAI and fAPAR sensors via radiative transfer modelling. We present the inital results from explicitly characterising and reconstructing a deciduous forest stand.

\section{MATERIALS AND METHOD}

\subsection{Study Area and data collection}

Our study site is a 6 ha deciduous forest at Wytham, Oxford, UK, which is dominated by Acer pseudoplatanus, Fraxinus excelsior and Corylus avellana. TLS and PAI data were collected representing full leaf-on conditions during the summer of 2015 and leaf-off conditions during winter 2015/16.

Terrestrial laser scanning data were collected with a RIEGL VZ-400 terrestrial laser scanner at 176 scan locations within an approximate $20 \times 20 \mathrm{~m}$ regular grid pattern across the study area (see figure 1). Multiple single scans made at different locations reduce occlusion and were coregistered using high reflectivity targets that act as tie-points between different scans. The RIEGL VZ-400 has a wavelength of $1550 \mathrm{~nm}$ and the beam divergence is nominally 0.35 mrad. We used an angular sampling of $0.04^{\circ}$ in both zenith and azimuth direction. Several passive sensing instruments were used to collect PAI data in the field, including digital hemispherical photography (DHP), Li-Cor LAI-2000 and 
LAI-2200. We used the VALERI sampling design for these PAI measurements (1800 measurements in total).

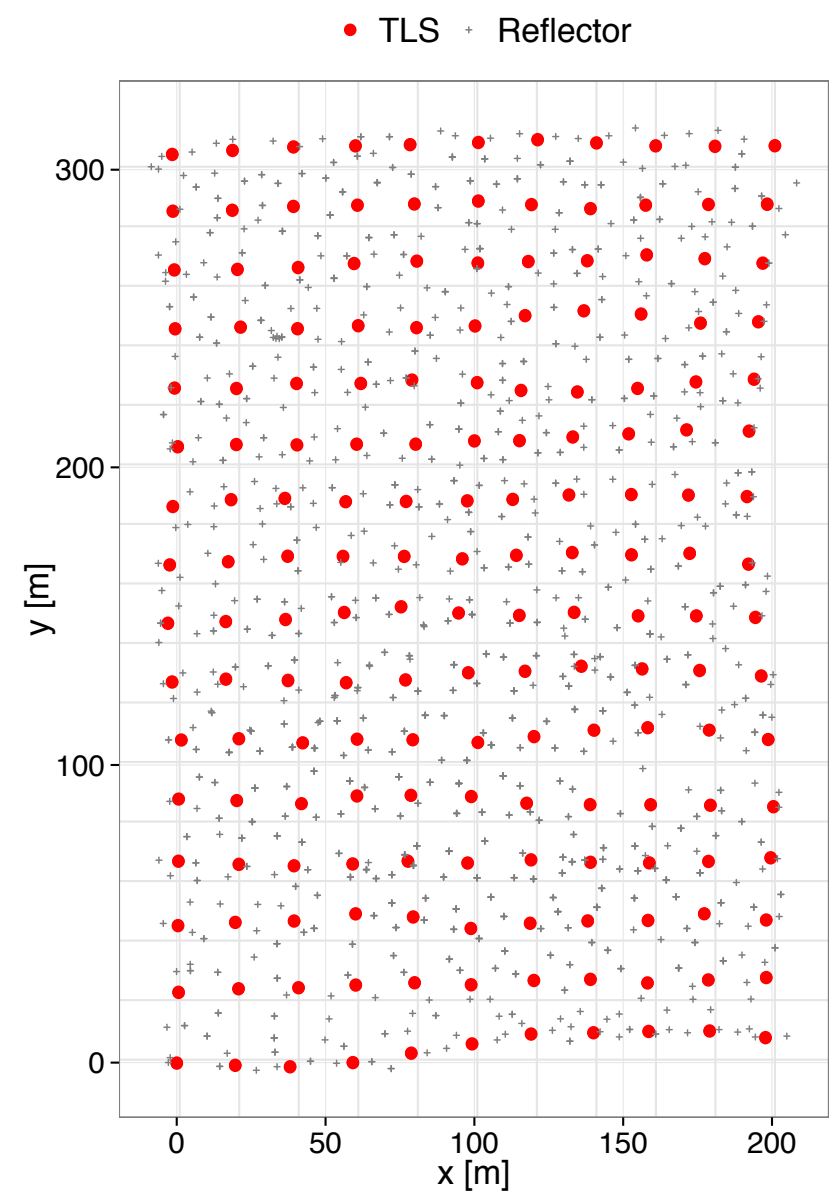

Fig. 1. Layout of the terrestrial laser scanning locations and the reflectors that were used as targets to co-register individual scan locations in Wytham Woods (summer fieldwork).

The PAR sensor network covers an area of approximately $150 \mathrm{~m}^{2}$. The wireless network layout replicates a hexagonal pattern with sensors located at $30 \mathrm{~m}$ intervals to avoid autocorrelation. The network records four-flux fAPAR (incoming and reflected above and below the canopy) using 62 below canopy sensors and two above canopy sensors. Each point in the network consists of two Apogee sensors that measure the soil reflected and canopy transmitted PAR component simultaneously. The above-canopy pair records the sky irradiance and canopy reflected PAR component.

\subsection{Forest stand reconstruction and radiative transfer modelling}

In this study we use the librat Monte Carlo ray tracing model [8], which has been tested in previous studies against observations as well as against other radiative transfer models. This model requires a 3D explicit description of the forest structure, and spectral information about the canopy constituents used to represent the forest structure. Field measurements using a FieldSpec (ASD Inc.) were collected to provide the spectral characteristics of the leaves, bark and understory (in summer and winter).

We will reconstruct tree models from TLS data and use the quantitative structure model (QSM) approach in $[5,6]$ to model the branching architecture. Addition of the leaves will be based on the derived light availability extracted from the point cloud and comparison of the leaf-on and leaf-off scan data. Figure 2 shows an example of a QSM model derived from TLS data for a single tree in Wytham Woods using the same methodology described in [6]. The leaf-on TLS data will be filtered using a clustered region growing approach alongside form pruning to exploit the fuzzy appearance of leaf returns due to leaf arrangement, incidence and clumping. This will broadly allow the delineation of wood and leaf returns. The leaf-off point cloud will be used to test how well these algorithms perform.

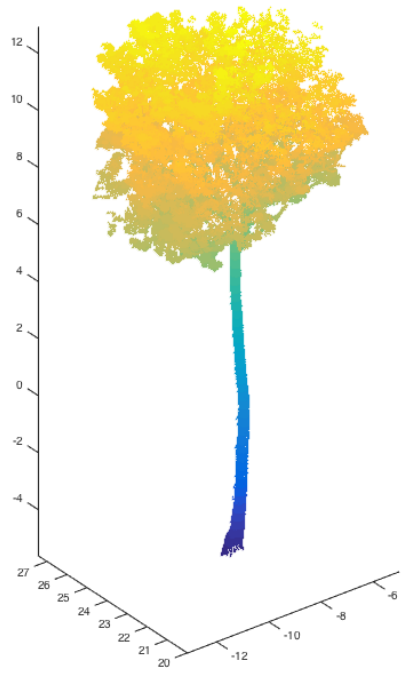

(a) TLS point cloud

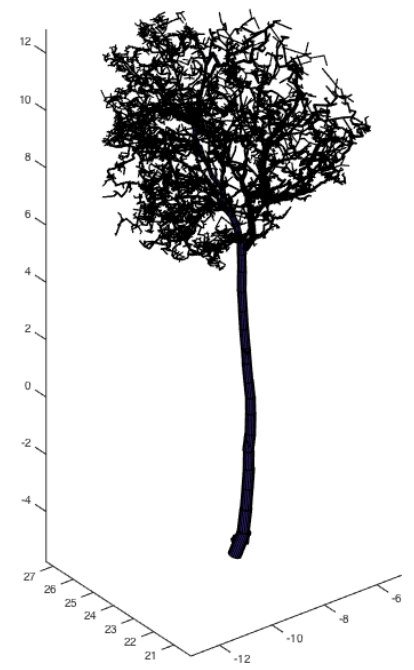

(b) QSM model
Fig. 2. QSM model derived from TLS data for a single tree in Wytham Woods.

\section{EXPECTED OUTCOMES}

The various PAI and fAPAR field instruments used here have been radiometrically and geometrically characterised, allowing calibration information to feed directly into the simulation framework process. Hence, this work provides, for the first time, an explicit framework for quantifying end-to-end traceability of various in situ fAPAR and PAI estimates through radiative transfer modelling, forest stand reconstruction from TLS data and comparison of field estimates with simulations. 
To our knowledge, this study is the first TLS data acquisition and $3 \mathrm{D}$ reconstruction of a large ( $>1 \mathrm{ha}$ ) study site that can be used in a RT model to calibrate and validate groundbased, airborne and spaceborne sensors. Such large-area realistic 3D calibration sites are especially important for planned spaceborne missions that measure forest structure directly using LiDAR (e.g. Global Ecosystem Dynamics Investigation Lidar, GEDI) or radar (e.g. Earth Explorer Biomass). Furthermore, the intense sampling strategy that was deployed in the field will enable us to address spatial variance and quantify the effect of different sampling designs on the inferred ECVs.

\section{ACKNOWLEDGMENTS}

The research leading to these results was funded through the Metrology for Earth Observation and Climate project (MetEOC-2), grant number ENV55 within the European Metrology Research Programme (EMRP). The EMRP is jointly funded by the EMRP participating countries within EURAMET and the European Union. We thank A. Barker, T. Jackson, S. Krishna Moorthy Parvathi, M. Boni Vicari and D. Fox for their assistance with fieldwork.

\section{REFERENCES}

[1] G.-R. Walther, E. Post, P. Convey, A. Menzel, C. Parmesan, et al., "Ecological responses to recent climate change," Nature, vol. 416, pp. 389395, 2002.

[2] G.J. Newnham, J.D. Armston, K. Calders, M.I. Disney, J.L. Lovell, C.B. Schaaf, A.H. Strahler, , and F.M. Danson, "Terrestrial laser scanning for plot scale forest measurement," Current Forestry Reports, vol. 1, pp. 239-251, 2015 .

[3] J.-F. Côté, J.-L. Widlowski, R. A. Fournier, and M. M. Verstraete, "The structural and radiative consistency of three-dimensional tree reconstructions from terrestrial lidar," Remote Sensing of Environment, vol. 113, pp. 10671081, 2009.

[4] J.-F. Côté, R. A. Fournier, G. W. Frazer, and K. O. Niemann, "A fine-scale architectural model of trees to enhance lidar-derived measurements of forest canopy structure," Agricultural and Forest Meteorology, vol. 166-167, pp. 72-85, 2012.

[5] P. Raumonen, M. Kaasalainen, A. Markku, S. Kaasalainen, H. Kaartinen, M. Vastaranta, M. Holopainen, M. Disney, and P. Lewis, "Fast automatic precision tree models from terrestrial laser scanner data," Remote Sensing, vol. 5, pp. 491-520, 2013.
[6] K. Calders, G. Newnham, A. Burt, S. Murphy, P. Raumonen, M. Herold, D. Culvenor, V. Avitabile, M. Disney, J. Armston, and M. Kaasalainen, "Nondestructive estimates of above-ground biomass using terrestrial laser scanning," Methods in Ecology and Evolution, vol. 6, pp. 198-208, 2015.

[7] J. Hackenberg, H. Spiecker, K. Calders, M. Disney, and P. Raumonen, "Simpletree - an efficient open source tool to build tree models from tls clouds," Forests, vol. 6, pp. 4245-4294, 2015.

[8] P. Lewis, "Three-dimensional plant modelling for remote sensing simulation studies using the Botanical Plant Modelling System," Agronomie, Agriculture and Environment, vol. 19, pp. 185-210, 1999. 